\title{
Radiation as a Public Health Problem
}

\author{
DAVID E. PRICE, M.D.
}

$\mathbf{T}$ 10 BE CLASSIFIED as a public health problem, a hazard must bear an important relationship to human health or disease. It must, furthermore, affect a significant part of the population, and it must be amenable to remedial action which is within the power of society to undertake.

Unquestionably, ionizing radiation meets the first two of these criteria. It has a relationship to human health and affects a significant part of the population. However, the design of social action deserves thoughtful consideration.

Past experience in public health has taught us that a problem usually becomes rather serious before people band together to deal with it. Only when a considerable amount of disease could be traced to polluted water did we begin to develop sewage treatment and other antipollution measures. Only when motor accidents had taken an alarming toll did citizens insist on better roads, safety devices, and various accident prevention programs. Traditionally, and in the main this is probably one of mankind's happier traits, we do not go looking for trouble. Not until the trouble looms so large it can no longer be ignored do we find the incentive to band together and pool resourcesneighborhood, city, State, or Nation-to do something about it.

In dealing with the health hazards of ionizing radiation, unfortunately, this traditional approach cannot promise success. The effects of ionizing radiation are cumulative and irreversible. They are subtle and may become ap-

Dr. Price, chief of the Bureau of State Services, Public Health Service, delivered this address at a symposium of the American Association for the Advancement of Science, Indianapolis, December 30, 1957. parent only after long delay. If we wait until there are obvious signs of radiation damage it will be too late to help the affected population or to decontaminate the polluted environment successfully. In this situation, prevention is not merely desirable, it is imperative.

Finding the proper incentive to stimulate preventive action, however, is not easy. In my opinion, to use fear as the incentive for action is not only unwarranted and undesirable, but useless. Panic or hysteria seldom results in constructive activity. Factual information may stimulate constructive public action. The public should know what public health workers are doing to promote radiological health and what more they think they ought to be doing.

Since we do not yet know at what point the harmful effects of prolonged, low-level exposure may outweigh the benefits of manmade radiation, we suggest that all unnecessary radiation exposure should be avoided. Consequently, much of our efforts in public health thus far are being directed toward finding what exposure is unnecessary and how it can be avoided.

\section{Reducing $X$-ray Exposure}

One of the major sources of radiation exposure today is the $\mathrm{X}$-ray. If we can reduce needless exposure to $\mathrm{X}$-ray without reducing its manifold benefits in the detection and treatment of disease, we have taken a significant step toward reducing the dimensions of the radiation exposure hazard. Much health agency activity in the radiological field is currently directed toward this goal.

For example, public health agencies for several years have been making a concerted drive to eliminate the use of the fluoroscopic shoe- 
fitting machine. This machine serves absolutely no practical purpose. Moreover, if a child uses it each time he gets a new pair of shoes, he gets a considerable dosage of radiation over the years particularly since many of these machines deliver a scattered dose over a rather large part of the body. This is obviously a source of radiation that can be eliminated without the sacrifice of any beneficial result. The shoe industry has been cooperative. Shop owners, once they are fully informed of the facts, seldom show any reluctance to remove these machines. The main reason this type of shoe-fitter continues to be used is because there are not enough people, health officials or others, who have the information, the time, and the interest to work on the drive to eliminate this hazard.

Another example of unnecessary exposure is the indiscriminate use of the X-ray in tuberculosis surveys. When tuberculosis was more widely prevalent, communitywide mass $\mathrm{X}$-ray surveys were justified. The early case finding from such surveys has unquestionably saved thousands of lives. There are still communities in the United States today where the prevalence of the disease makes mass $\mathrm{X}$-ray campaigns desirable. However, there are other groups of people among whom the disease is so rare that the mass $\mathrm{X}$-ray approach is no longer the best case-finding method. Consequently, the Public Health Service has recently recommended a more selective use of this procedure.

Interestingly enough, when this recommendation was publicly announced, it was interpreted by some as implying that mass $\mathrm{X}$-rays were especially hazardous and that the Public Health Service opposed their use. This is an example of the emotional exaggeration that creates unwarranted fears and hampers constructive efforts to promote health objectives. Any general reluctance on the part of the public to accept diagnostic $\mathrm{X}$-rays, when recommended by responsible authorities, would certainly be far more injurious to health than would the slight additional amount of radiation exposure. The vast majority of papers and other mass media made it clear that the individual $\mathrm{X}$-ray in itself is not hazardous and that in areas where tuberculosis is prevalent mass $\mathrm{X}$-ray surveys are still a valuable case-finding technique.

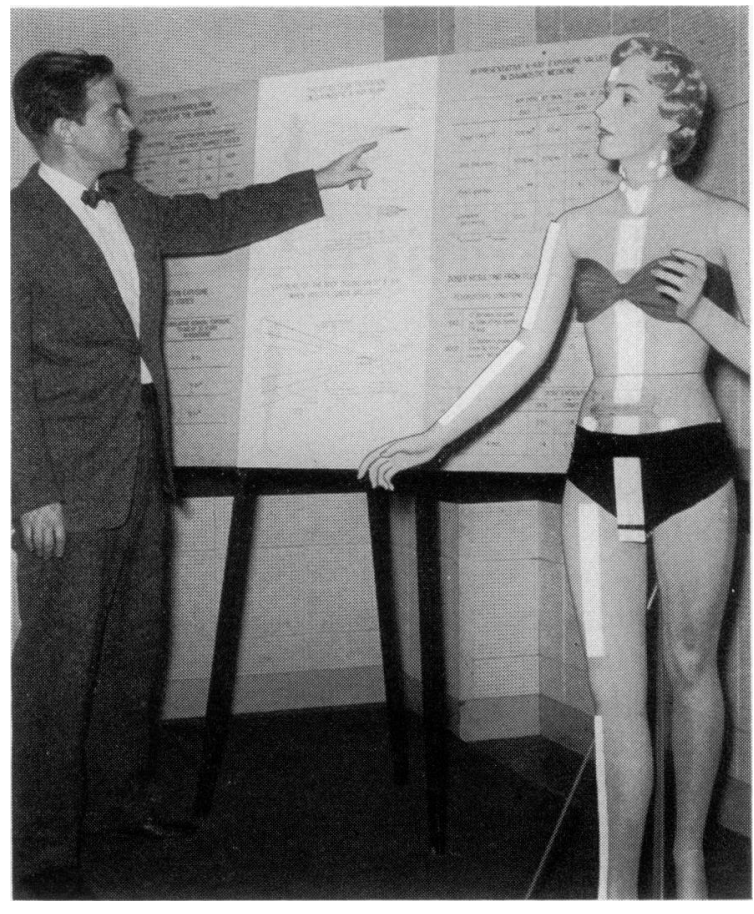

(Above) Without impairment of X-ray pictures, technicians adjust cones, filters, distance, and voltage so as to reduce radiation doses as much as 75 percent. The white strips on the model fluoresce under radiation to indicate exposure of strategic tissues, during demonstrations of X-ray techniques conducted by the Public Health Service. Dr. Walter Stahl points to charts (opposite page) which explain the value of these adjustments. Accompanying tables show the dose to different organs under various conditions.

(Top right) An aluminum plate absorbs soft X-rays, which lack energy to pass through the patient directly to the radiographic plate. Soft X-rays fuzz the $\mathrm{X}$-ray picture and contribute an unnecessary dose to the patient. A cone, absent here, would further confine the dose.

(Below right) Too large a cone, or complete absence of a cone, permits beams intended for a chest plate to strike organs which should be protected. Even with a correct cone, irrelevant portions of the body may receive a radiation dose if the tube is too far from the patient. 

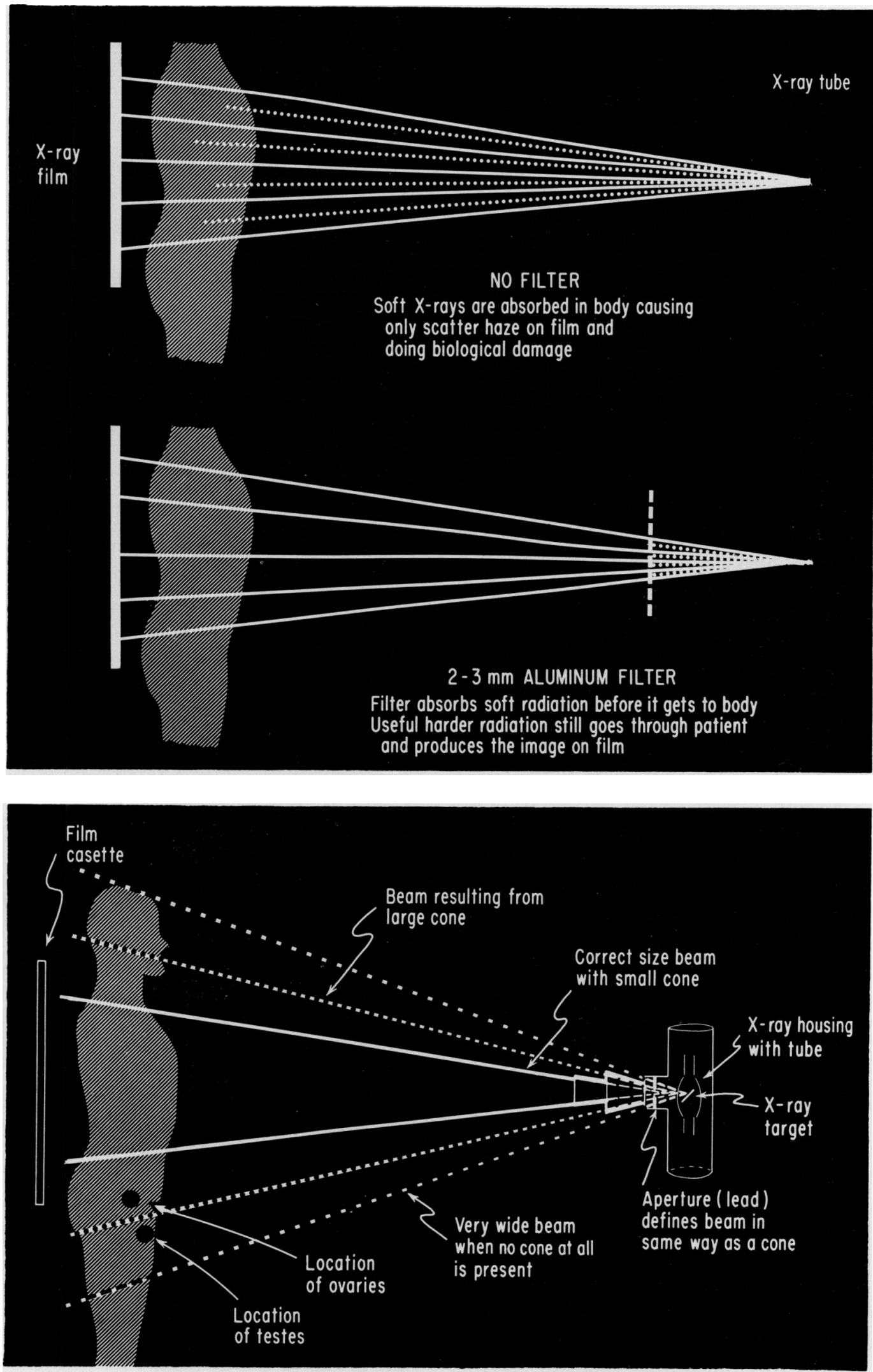
A third example of the opportunity to reduce unnecessary exposure to X-ray lies in the reduction of the radiation doses delivered in medical and dental examinations. It is an unfortunate fact that many of the more than $160,000 \mathrm{X}$-ray machines being used in the healing arts today deliver a higher dose of radiation than is necessary. There is room for much improvement both in the machines themselves and in the techniques of their use. To drive home this point, our radiologists use a wax model taped and instrumented to show radiation dosage. They take a chest $\mathrm{X}$-ray with typical equipment and employ a commonly used technique. Then, changing the cone of the machine, focusing more precisely, and making a few other adjustments, they take an equally useful film, but expose the monitored tissues to only $1 / 35$ th as much radiation.

Several studies now under way within the Public Health Service are designed to perfect techniques that will produce films of maximum value with minimum exposure and to provide better measurement of the doses delivered. Hand in hand with such studies, however, must go the training of technicians to make use of the equipment and procedures which are already available and which reduce substantially the radiation dosage received by both the patient and the operator.

Other studies are being carried out by public health personnel at all levels of government to reduce unnecessary X-ray exposure. As more physicians, dentists, and other members of the healing arts become aware of all that they can do to prevent unnecessary exposure, the $\mathrm{X}$-ray hazard can be controlled. The problem is primarily one of research and of getting the findings of such research to professional groups, most of whom will readily understand their significance and apply them to their practice.

\section{Measuring Environmental Radiation}

The development of nuclear energy brings new significance to every effort to minimize exposure so that hazards may be balanced against the benefits of radiation not only in the healing arts but also in industry.

Therefore, along with drives against unnecessary $\mathrm{X}$-ray exposure, health agencies are con-

\section{New Radiological Health Division}

On recommendation of the Surgeon General and approval of the Secretary of Health, Education, and Welfare, a Division of Radiological Health has been set up in the Bureau of State Services with Francis J. Weber, M.D., as chief. Dr. Weber, a commissioned officer of the Public Health Service, comes from Region 8, Department of Health, Education, and Welfare, Denver, Colo., where he was regional medical director.

cerning themselves with environmental sources of radiation.

Before he split the atom, man gave little thought to the background radiation in nature. Consequently, although we know that there is great variation in the background radiation of different localities, we have little information about what these levels are for any given area or for its air, water, or food. Obviously, it is necessary to have such information in order to determine how much radiation manmade sources are adding to the environment. Moreover, the time when we can obtain such data is fast slipping away. Ideally, these baseline studies should have been made before the first atom was split. Nevertheless, if we get this information as rapidly as possible, it will still be extremely valuable in helping us to make better health evaluations of exposure doses.

Baseline data are now being obtained on a limited scale. The focus of most of these monitoring activities is within the Atomic Energy Commission. However, the Public Health Service, in cooperation with State health departments and community groups, has operated for the past 5 years some 100 air and rain surveillance stations in order to measure community air pollutants, including radioactive pollutants. More recently, the Service has established about 40 stations for surveillance of water pollution. Here, too, analysis of collected samples includes radioactive pollution. The only food study in which the Public Health Service is currently participating is the collection and analysis of milk for strontium-90 and other radioactive elements. These studies are being conducted in five major milk shed areas. 
The Food and Drug Administration is conducting other limited surveys. All of these baseline studies need to be expanded . . . now.

Baseline data are needed as a guide in the selection of reactor sites and as a gauge for determining how much and how rapidly radioactive waste from industry and from fallout is being added to the environment in any given area.

Such data may also prove helpful in the development of epidemiological studies. To date, studies of permissible radiation doses have been based primarily on observations of persons exposed to abnormally high radiation dosages and are, at best, estimates. In order to evaluate the public health significance of radiation, we need to devise means of measuring the far more subtle effects of prolonged, low-level exposure. Since the damage from this type of exposure extends over years and generations, the difficulties of the measurement task are too obvious to need delineation here. We place a high priority on such research. The information is needed not only to provide a better basis for establishing practical radiation dose limits but also to relieve the public of those exaggerated fears which inevitably occur when one is dealing with unknowns.

The increasing public awareness and concern about radiation exposure has been focused primarily on the matter of weapons testing. A far more important potential source of environmental radiation exposure is the rapidly growing number of power reactors based on nuclear fission. For this reason, long before the Shippingport, Pa., atomic power plant began operating in December 1957, health personnel, both Federal and State, were working closely with the designers of that installation. Radiation specialists from the Public Health Service and the Pennsylvania Health Department participated in planning the installation and operation of the waste treatment system at the Shippingport reactor. This collaboration includes baseline studies of the Ohio River system, the receiving stream.

The Shippingport operation has given industry, the Atomic Energy Commission, and the Federal-State health services an excellent opportunity to work out a practical pattern of cooperation in the interest of public health safety. This cooperation will continue, and operating experience will provide an opportunity to test theory against practice.

A pioneering operation such as this naturally commands the careful and personal attention of highly trained experts. But what is going to happen as the industry expands? Will the same precautions always be taken? Traditionally, State agencies, and in most States, it is the health department, have assumed responsibility for seeing that every industry within their jurisdiction operates in such a way as not to endanger the health of the workers or of the other citizens of the community. Public health supervision of radiation sources in industry is therefore not a totally new concept. It fits into the existing pattern of industry and health department relationships. But it does present new challenges.

Will States and communities accept these challenges in time? To date, there are radiological health programs in only a few State health departments. All States need them. To date, only a few communities have any accurate idea of the sources and amounts of radiation to which their people are exposed. Every community should be taking this first step of assessing the radiation burden.

It will not long be feasible for the public to rely entirely on the users of radiation sources for assurance of community health protection. As nuclear sources of power begin to compete with conventional sources, there will undoubtedly be severe economic pressures to lower operating and capital costs. The public health agencies should be prepared to assure that such economies are not made at the expense of public health considerations.

\section{Three Major Challenges}

Summing up, radiation presents three major challenges to the public health profession. First, the public must be alerted to the need for greatly expanded radiological health programs which can provide security from fears that would hamper the constructive development of atomic industry and atomic medicine. Public linderstanding is basic because adequate radiological health programs require both legal au- 
thority and financial support on a scale possible only when there is general public acceptance.

The second big problem is that of trained manpower. Radiological health is a specialized field with concepts, vocabulary, units of measurement, and sensitive instrumentation of its own. With the increase of radiation sources, there must be a corresponding growth in health personnel who have the training required to provide planning, surveillance, and other services. However, since highly trained specialists are produced slowly and since there is much to be done right now, the Public Health Service is providing practical training to the existing staffs of State and local health departments. This is done by courses and seminars designed to instruct trainers, persons who can conduct similar programs in their own areas. In addition, the corps of specialists needed as teachers and researchers must be increased. For this task, we look to our colleges and universities.
The third major need is research. I have touched upon the need to know the probable doses and the biological effects. The engineering field is presented with equally momentous challenges. For example, we have yet to find a satisfactory and economical method of disposing of high-level radioactive waste. The Atomic Energy Commission already has more than 65 million gallons of radioactive waste buried in tanks in the earth. As the Nation becomes dotted with nuclear energy plants, what is to be done with these high-level wastes? We are getting by at present with temporary expedients; we must seek long-range solutions.

In conclusion, I say again that, from a public health standpoint, radiation is still a preventable health hazard. I believe we can keep it so, if we act now. Since we recognize that all radiation is harmful and that its effects are cumulative and irreversible, the price of delay in the vigorous pursuit of research and control efforts might well prove to be intolerably high.

\section{Graduate Fellowships in Public Health}

Through projects in Massachusetts, Louisiana, and California, fellowships of $\$ 2,500$ are available for the second year of graduate study to social workers interested in the field of public health.

With assistance from the Children's Bureau, the health departments of the States have set up educational programs focused on social work practice in public health, in schools of social work. Participating are the schools of social work at Boston College, Boston University, Simmons College in Boston; Tulane University School of Social Work; and the University of California School of Social Welfare, Berkeley.

The University of California is also offering fellowships of $\$ 3,600$ for a year of supervised practice in public health following completion of the second graduate year.

Further information about these fellowships may be obtained by writing to the dean of any of these schools of social work. Applications should be made before April 15, 1958. 